\title{
Relative Bioavailability of a Fixed-Combination Tablet Formulation of Azithromycin and Chloroquine in Healthy Adult Subjects
}

\author{
Qinying Zhao*, Vivek Purohit, Jenny Cai, Robert R. LaBadie and Richa Chandra
}

Pfizer Inc, Groton, Connecticut, USA

\begin{abstract}
A fixed-dose combination of azithromycin and chloroquine (AZCQ) is in development for intermittent preventive treatment of malaria in pregnant women (IPTp). The combination has demonstrated synergistic activity against chloroquine-resistant strains of Plasmodium falciparum in vitro and in vivo and efficacy in Phase 2 and 3 treatment studies in patients with symptomatic uncomplicated $P$. falciparum malaria. This was an open-label, randomized, single-dose, parallel-group study to estimate the relative bioavailability of two AZCQ tablets, each containing azithromycin base $250 \mathrm{mg}$ and chloroquine base $155 \mathrm{mg}$ (test treatment), compared with the coadministration of commercially available individual tablets of azithromycin base $500 \mathrm{mg}$ and chloroquine base $300 \mathrm{mg}$ (reference treatment) in 40 healthy male and female subjects (aged 18-55 years; body weight $>50.0 \mathrm{~kg}$ ). Fasting subjects were randomized 1:1 to receive either test or reference treatment. Blood samples for the determination of serum azithromycin and plasma chloroquine concentrations were collected at specified time points pre- and post-dose for noncompartmental pharmacokinetic analyses. Safety evaluations included monitoring adverse events and vital signs as well as performing clinical laboratory tests. All subjects completed the study. Area under the concentrationtime curve from time zero to time of last measurable concentration ( $A \cup C_{\text {tat }}$ ) of azithromycin and chloroquine for the two AZCQ tablets was comparable to the reference treatment. The relative bioavailability as measured by $\mathrm{AUC}_{\text {las }}$ ratio of adjusted geometric means (90\% confidence interval) for the two AZCQ tablets was $101 \%(85.4 \%, 119 \%)$ for azithromycin and $99.1 \%(84.0 \%, 117 \%)$ for chloroquine compared with the reference treatment. Maximum concentration values for the two AZCQ tablets were approximately $13.0 \%$ higher for azithromycin and $11.0 \%$ lower for chloroquine compared with reference treatment. Both treatments were well tolerated. This AZCQ tablet formulation is currently being evaluated in Phase 3 clinical trials for IPTp.
\end{abstract}

Keywords: Azithromycin; Chloroquine; Bioavailability; Pharmacokinetics

Abbreviations: AE: Adverse Event; $\mathrm{AUC}_{\text {last }}$ : Area Under The Concentration-Time Curve from Time Zero to Time of Last Measurable Concentration; AZ: Azithromycin; AZCQ: Fixed-Dose Combination Tablet of Azithromycin and Chloroquine; CI: Confidence Interval; $\mathrm{C}_{\max }$ : Maximum Concentration; CQ: Chloroquine; CV: Coefficient of Variation; HPLC-MS/MS: High-Performance Liquid Chromatography Tandem Mass Spectrometry; IPTp: Intermittent Preventive Treatment of Malaria in Pregnant Women; K3EDTA: Tri-Potassium Ethylene Diamine Tetra-Acetic Acid; PK: Pharmacokinetics; SP: Sulfadoxine Pyrimethamine; $\mathrm{T}_{\max }$ : Time To Maximum Concentration

\section{Introduction}

Malaria in pregnancy is one of the most common preventable causes of maternal and neonatal mortality and morbidity in developing countries; approximately 125 million pregnancies are at risk every year [1]. Sulfadoxine-pyrimethamine (SP) is the current standard of care for intermittent preventive treatment of malaria in pregnant women (IPTp) in areas with high and stable malaria transmission [2]. AZCQ, a fixed-dose combination tablet of azithromycin (AZ) and chloroquine (CQ), is being developed for IPTp as a potential alternative to SP.

There is a strong rationale for developing AZCQ for IPTp. First, the combination of $\mathrm{AZ}$ and $\mathrm{CQ}$ has demonstrated synergistic activity against CQ-resistant strains of Plasmodium falciparum in vitro and in vivo [3-5]. Coadministration of $\mathrm{AZ}$ and $\mathrm{CQ}$ has demonstrated over $95 \%$ efficacy in Phase 2 and 3 clinical trials in Africa, Latin America, and India, irrespective of the rates of CQ resistance [4,6,7]. Furthermore, $\mathrm{AZ}$ and CQ have been on the market for many years individually and have extensive safety data in adults, children, and pregnant women [8]. The safety of the combination/coadministration of AZ and CQ has been documented in more than 1,000 subjects [8]. Additionally, there is no evidence of a clinically relevant pharmacokinetic $(\mathrm{PK})$ interaction between AZ and CQ in healthy subjects [9]. Finally, the growing resistance to SP has become a cause of serious concern, especially in East and South Africa, and there is an urgent need to develop alternatives to SP [10].

AZCQ, a combination of AZ base $250 \mathrm{mg}$ and CQ base $155 \mathrm{mg}$, has been developed specifically for use in IPTp and is likely to provide a convenient dosage form with improved compliance. The aim of this study was to evaluate the relative bioavailability of AZCQ tablets compared with coadministered commercially available individual tablets of $\mathrm{AZ}$ and $\mathrm{CQ}$ in healthy adult subjects (ClinicalTrials.gov identifier NCT00844207).

\section{Methods}

\section{Study design and subjects}

This study was an open-label, randomized, single-dose, parallel-

*Corresponding author: Qinying Zhao, PhD, Director of Clinical Pharmacology, Medical Development Group in Emerging Markets and Established Products Pfizer Inc, 445 Eastern Point Road, MS8260-2112, Groton, CT 06340, USA; Tel: 860-441-1497; E-mail: qinying.zhao@pfizer.com

Received September 28, 2012; Accepted November 22, 2012; Published November 26, 2012

Citation: Zhao Q, Purohit V, Cai J, LaBadie RR, Chandra R (2013) Relative Bioavailability of a Fixed-Combination Tablet Formulation of Azithromycin and Chloroquine in Healthy Adult Subjects. J Bioequiv Availab 5: 001-005. doi:10.4172/ jbb.1000127

Copyright: (c) 2013 Zhao Q, et al. This is an open-access article distributed under the terms of the Creative Commons Attribution License, which permits unrestricted use, distribution, and reproduction in any medium, provided the original author and source are credited. 
group clinical pharmacology study. Healthy male and female subjects aged 18 to 55 years with body mass index 17.5 to $30.5 \mathrm{~kg} /$ $\mathrm{m}^{2}$ and total body weight greater than $50.0 \mathrm{~kg}$ were included in the study. Individuals with evidence of illness before study treatment (fever within 5 days before the first dose, acute or chronic infectious disease within 15 days before the first dose of study treatment) were excluded from participation. Additional exclusion criteria included any condition possibly affecting drug absorption; treatment with an investigational drug within 30 days or five half-lives before the first dose of study treatment; use of prescription or nonprescription drugs and/or dietary supplements within 7 days or five half-lives before the first dose of study treatment; excessive use of tobacco- or nicotinecontaining products (equivalent of more than five cigarettes per day) or a history of regular alcohol consumption within 6 months of screening; electrocardiogram demonstrating corrected QT interval greater than $450 \mathrm{msec}$ at screening; history of significant cardiovascular disease; or history of intolerance to AZ or CQ. Females who were pregnant or nursing were also excluded.

Subjects were randomized in a 1:1 ratio to one of the following single-dosage treatments given at approximately 8:00 AM ( \pm 2 hours) after an overnight fast of 8 hours. Treatment A (test treatment) included two AZCQ tablets (AZ base $250 \mathrm{mg} / \mathrm{CQ}$ base $155 \mathrm{mg}$ for each tablet $\times 2)^{*}$. Treatment $B$ (reference treatment) included a single commercially available tablet of AZ (Zithromax ${ }^{\circledR}$, Pfizer Inc, New York, NY) containing a 500-mg dose base and a single tablet of CQ (Aralen $^{\circledR}$, Sanofi Aventis, Bridgewater, NJ) containing a 300-mg dose base. Subjects were confined to the clinical research unit for at least 2 days, with follow-up visits on Days 3, 4, and 5 for PK blood sample collections.

Systemic exposure parameters (maximum drug concentration $\left[\mathrm{C}_{\max }\right]$, area under the drug concentration-time profile from time zero to the time of last quantifiable concentration $\left[\mathrm{AUC}_{\text {last }}\right]$ ) for $\mathrm{AZ}$ and CQ were calculated and compared between the two treatment groups. Time to $\mathrm{C}_{\max }\left(\mathrm{T}_{\max }\right)$ was also estimated. Because of the long half-life of both $\mathrm{AZ}$ and CQ, a crossover study design would have been logistically challenging due to long trial duration and potential subject withdrawals. Therefore, the two treatments were administered in a parallel manner, and blood samples were collected at specified time points from both groups for 96 hours post dose.

This study was conducted in compliance with the ethical principles originating in or derived from the Declaration of Helsinki and in compliance with all International Conference on Harmonisation Good Clinical Practice guidelines. The study protocol and consent documentation were reviewed and approved by the Institutional Review Board at the participating study center, a fully accredited board located in Austin, Texas. All subjects provided informed consent before entering the study.

*The $60 \%$ potency factor due to rounding has historically been used by the manufacturer of the chloroquine phosphate tablets, Aralen ${ }^{\circledR}$ (Sanofi-Synthelabo, Bridgewater, $\mathrm{NJ}$ ), whereas the more recent Avloclor ${ }^{\circledR}$ (AstraZeneca,Wilmington, $\mathrm{DE}$ ) uses the stoichiometric potency factor of $62.0 \%$ (molecular weight [MW] of chloroquine free base of $319.87 / \mathrm{MW}$ chloroquine phosphate of $515.86=0.6201$ ) Therefore, the actual potency factor based on stoichiometry is $62.0 \%$ chloroquine base in chloroquine phosphate. Pfizer used the $62.0 \%$ chloroquine potency factor and a label claim of $155 \mathrm{mg}$ chloroquine base in the fixed-dose AZCQ combination tablet. As a result, $2 \times 155 \mathrm{mg}$ chloroquine base from 2 fixed-dose Pfizer $A Z C Q$ combination tablets $\left(310 \mathrm{mg}^{*} 60 \% / 62 \%=300 \mathrm{mg}\right)$ and $300 \mathrm{mg}$ chloroquine base in Aralen ${ }^{\circledR}$ have equal dose of chloroquine base.

\section{Pharmacokinetic evaluations}

Blood samples $(3 \mathrm{~mL})$ for determination of $\mathrm{AZ}$ concentrations in serum were collected into appropriately labeled tubes containing no preservative or anticoagulant or serum separator at pre-dose and at $0.5,1,2,3,4,6,8,12,16,24,36,48,72$, and 96 hours post dose. The whole blood samples remained at room temperature until clotted (approximately 30 minutes). Samples were then centrifuged at $1,700 \mathrm{X}$ $\mathrm{g}$ for approximately 10 minutes at $4^{\circ} \mathrm{C}$. The serum was transferred into appropriately labeled screw-capped polypropylene tubes and stored at $-20^{\circ} \mathrm{C}$ within 1 hour of collection. Serum samples were analyzed for $\mathrm{AZ}$ concentrations using a validated high-performance liquid chromatography with tandem mass spectrometry (HPLC-MS/MS) assay.

In addition, blood samples $(4 \mathrm{~mL})$ for determination of CQ concentrations in plasma were also collected into appropriately labeled tubes containing tri-potassium ethylene diamine tetra-acetic acid (K3EDTA) at pre-dose and at $0.5,1,2,3,4,6,8,12,16,24,36$, 48,72 , and 96 hours post dose. Samples were centrifuged at $1,700 \mathrm{X}$ g for approximately 10 minutes at $4^{\circ} \mathrm{C}$. The plasma was transferred into appropriately labeled screw-capped polypropylene tubes and stored at $-20^{\circ} \mathrm{C}$ within 1 hour of collection. Samples were analyzed for determination of $\mathrm{CQ}$ concentrations using a validated liquid chromatography with tandem mass spectrometry (LC-MS/MS) assay. The evaluated PK parameters are detailed in table 1.

\section{Analytical methods}

Bioanalytical Systems Ltd (Warwickshire, UK) analyzed serum samples for AZ concentrations using a HPLC-MS/MS method, following a liquid-liquid extraction. For the serum sample, $100 \mu \mathrm{L}$ of D3-azithromycin (internal standard, $50.0 \mathrm{ng} / \mathrm{mL}$ ) in acetonitrile-water ( $1: 1 \mathrm{vol} / \mathrm{vol}$ ) was added to $50 \mu \mathrm{L}$ of serum, followed by the addition of $50 \mu \mathrm{L}$ of $50 \mathrm{mM}$ ammonia and $500 \mu \mathrm{L}$ of methyl tertiary butyl ether in a TomTec 96-well format. After brief vertexing (2 minutes), the samples were centrifuged at 4,000 rpm for $5 \mathrm{~min}$ to separate the layers. The upper ether layer was transferred to a 96-well plate and evaporated under nitrogen at $40^{\circ} \mathrm{C}$. The dried extract was reconstituted with 200 $\mu \mathrm{L}$ of the mobile phase (35\% acetonitrile $-65 \% 50 \mathrm{mM}$ ammonium, $\mathrm{vol} / \mathrm{vol}$ ). After brief vertexing ( 1 minute), the samples were centrifuged at 2,500 rpm for 5 minutes. A $50 \mu \mathrm{L}$ aliquot was injected into an LCMS/MS system (BAS PM-80 pump with an LC-26B on-line vacuum degasser and a PE Sciex API-3000 LC-MS/MS system) set up with a Zorbax Eclipse XDB-C 8 column $(2.1 \times 150 \mathrm{~mm}, 5 \mu \mathrm{m})$. The mass spectrometer was operated in the positive ionization mode and monitored the transition ions $\mathrm{m} / \mathrm{z} \quad 749.5 \rightarrow 591.4$ and $752.6 \rightarrow 594.1$ for $\mathrm{AZ}$ and D3-azithromycin, respectively. The dynamic range for the serum assay was 10.0 to $500 \mathrm{ng} / \mathrm{mL}$. The conditions for stability for freeze/thaw, matrix, processed extract, and long-term in frozen matrix were 3-cycles at -200C/ambient temperature, 25 hours at ambient

\begin{tabular}{|l|l|l|}
\hline Parameter & Definition & Method of Determination \\
\hline $\mathrm{C}_{\max }$ & Maximum drug concentration & Observed directly from data \\
\hline $\mathrm{T}_{\max }$ & Time to $\mathrm{C}_{\max }$ & $\begin{array}{l}\text { Observed directly from data } \\
\text { as time of first occurrence }\end{array}$ \\
\hline AUC $_{\text {last }}$ & $\begin{array}{l}\text { Area under the drug } \\
\text { concentration-time profile from } \\
\text { time zero to the time of last } \\
\text { quantifiable concentration }\end{array}$ & $\begin{array}{l}\text { Linear/log trapezoidal } \\
\text { method }\end{array}$ \\
\hline
\end{tabular}

Table 1: Pharmacokinetic parameters determined for azithromycin and chloroquine. 
temperature, 54 hours at ambient temperature, and 413 days at $-20^{\circ} \mathrm{C}$ $\pm 50^{\circ} \mathrm{C}$, respectively. The mean percent recovery for $\mathrm{AZ}$ was $100 \%$. The accuracy of the quality control samples used during the sample analysis ranged from $-2.1 \%$ to $4.7 \%$, with a precision of $2.5 \%$ to $4.7 \%$. In 11 analytical runs for all serum samples, all runs were acceptable.

Cetero Research (Houston, TX, USA) analyzed plasma samples for CQ concentrations using a LC-MS/MS method. CQ was determined following a liquid-liquid extraction. Each $200 \mu \mathrm{L}$ plasma sample was mixed with $1 \mathrm{~mL}$ of protriptyline hydrochloride (internal standard solution, $20.0 \mathrm{ng} / \mathrm{mL}$ ) and $50 \mu \mathrm{L}$ of $4.5 \mathrm{M}$ ammonium hydroxide solution. After vortexing, $5 \mathrm{~mL}$ of methyl tertiary butyl ether was added and the sample was shaken for 5 minutes and centrifuged for 5 minutes at 3,000 rpm. The organic layer was transferred to a culture tube and $20 \mu \mathrm{L}$ of $0.1 \%$ formic acid in methanol solution $\mathrm{w} 1: 1$. vol/vol) was added as added. The organic layer was evaporated to dryness at $400^{\circ} \mathrm{C}$ under a gentle stream of air. The dried extract was reconstituted with 1 $\mathrm{mL}$ of the mobile phase (mixture of $700 \mathrm{~mL}$ of methanol with $300 \mathrm{~mL}$ of deionized water and $2.5 \mathrm{~mL}$ of $1.0 \mathrm{M}$ ammonium trifluoroacetate solution) and $5 \mu \mathrm{L}$ was injected onto a LC-MS/MS system (PE Series 200 LC pump with API-3000/4000 LC-MS/MS system (equipped with Turbo Ion Spray) set up with a Beta Basic CN (Keystone) column $(2.1 \times 100 \mathrm{~mm}, 5 \mu \mathrm{m})$ equipped with In-line pre-column filter. The mass spectrometer was operated in the positive ionization MRM mode and monitored the transition ions $\mathrm{m} / \mathrm{z} \quad 320.2 \rightarrow 247.0$ and $264.1 \rightarrow 155.1$ for CQ and protriptyline, respectively. The dynamic range for the serum assay was 1.00 to $500 \mathrm{ng} / \mathrm{mL}$. The conditions for stability for freeze/ thaw, matrix, processed extract, and long-term in frozen matrix were 6-cycles at $-20^{\circ} \mathrm{C} \pm 10^{\circ} \mathrm{C} /$ ambient temperature, 24 hours at ambient temperature, 48 hours at ambient temperature, and 1886 days at $-20^{\circ} \mathrm{C}$ $\pm 10^{\circ} \mathrm{C}$, respectively. The mean percent recovery for CQ was $80.8 \%$. The accuracy of the quality control samples used during sample analysis ranged from $-0.4 \%$ to $3.0 \%$, with a precision of $8.9 \%$. In 11 analytical runs for all serum samples, all runs were acceptable.

\section{Safety evaluations}

Adverse events (AEs), clinical laboratory tests, and vital signs were monitored throughout the study. A complete physical examination, including 12-lead electrocardiogram, was done at screening and a limited physical examination was done on Day 5.

\section{Statistical methods}

The sample size of 40 subjects was empirically determined. However, 20 subjects per cohort would have provided a 90\% confidence interval (CI) for the difference between treatments of \pm 0.185 and \pm 0.218 for $\mathrm{AZ}$ and \pm 0.163 and \pm 0.160 for $\mathrm{CQ}$ on the natural log scale for $\mathrm{AUC}_{\text {last }}$ and $\mathrm{C}_{\max }$, respectively, with $80 \%$ coverage probability.

Three analysis sets were defined for this study: 1) PK concentration population, which included all randomized and treated subjects with at least one concentration; 2) PK parameter analysis population, which included all randomized and treated subjects with at least one PK parameter of primary interest; and 3) safety analysis set, which included all subjects who received at least one dose of study medication.

A one-way analysis of variance model was used to analyze natural log-transformed $\mathrm{AUC}_{\text {last }}$ and $\mathrm{C}_{\text {max }}$ of both $\mathrm{AZ}$ and CQ separately by analyte. Estimates of the adjusted mean differences (test-reference) and corresponding 90\% CI were obtained from the model. The adjusted mean differences and $90 \%$ CI for the differences were exponentiated to provide estimates of the ratios of adjusted geometric means (test/ reference) and $90 \%$ CI for the ratios. Relative bioavailability was estimated as the ratio of adjusted geometric means for test treatment and reference treatment for $\mathrm{AUC}_{\text {last }}$. $\mathrm{PK}$ parameters $\left(\mathrm{AUC}_{\text {last }}, \mathrm{C}_{\max }\right.$, and $\mathrm{T}_{\max }$ ) were summarized descriptively by analyte and treatment.

\section{Results}

\section{Subject disposition and demographics}

A total of 40 subjects were randomized and all completed the study (Table 2). Most $(34 / 40 ; 85 \%)$ subjects were male; the proportion of male and female subjects was broadly similar in the two groups. Mean age was approximately 35 years in both groups. Sixty percent $(24 / 40)$ of subjects were black; the distribution of race was similar in both groups. Mean weight, height, and body mass index were similar in the two groups.

\section{Pharmacokinetics}

Serum azithromycin pharmacokinetics: Mean and median serum AZ concentrations versus time profiles for the two treatment groups are presented as semi-log plots in figure 1a. The mean serum AZ concentration-time profiles with associated standard deviation (SD) are also presented as linear plots in figure $1 \mathrm{~b}$. The median drug concentrations between 30 minutes and 1 hour post dose were greater with the AZCQ tablet than with the coadministered commercially available individual tablets of $\mathrm{AZ}$ and CQ. After 3 hours post dose, the median serum AZ concentration-time profiles were approximately superimposable between the two treatment groups. The PK parameter values are descriptively summarized in table 3 , and statistical analysis results of serum AZ exposure parameter for bioavailability assessment are presented in table 4 . Variability in $\mathrm{AUC}_{\text {last }}$ (coefficient of variation [CV] 30\%-32\%) and $\mathrm{C}_{\max }(\mathrm{CV}, 38 \%-40 \%)$ estimates for $\mathrm{AZ}$ were similar between the two treatment groups (Table 3). The AUC $\mathrm{Ast}_{\text {last }}$ of $\mathrm{AZ}$ for the two AZCQ tablets was comparable to the reference treatment. The relative bioavailability of $\mathrm{AZ}$, ie, ratio of adjusted geometric means (90\% CI) of $\mathrm{AUC}_{\text {last }}$, for the two AZCQ tablets was 101\% (85.4\%, 119\%) compared with the reference treatment.

Maximum serum AZ concentrations were generally achieved by 0.5 to 3.0 hours post dose with both treatments (Table 3). The $\mathrm{C}_{\max }$ values of AZ for the two fixed-dose AZCQ tablets were approximately 13.0\% higher than achieved with the reference treatment (Table 4).

\begin{tabular}{|c|c|c|}
\hline Characteristic & $\begin{array}{l}\text { Combination Tablets } \\
\text { (2×Azithromycin } 250 \\
\text { mg/Chloroquine } 155 \\
\mathrm{mg}) \mathrm{n}=20\end{array}$ & $\begin{array}{l}\text { Individual Tablets } \\
\text { (Azithromycin } 500 \\
\text { mg+Chloroquine } 300 \mathrm{mg} \text { ) } \\
\mathrm{n}=20\end{array}$ \\
\hline $\begin{array}{l}\text { Age, years } \\
\text { Mean (SD) } \\
\text { Range (min-max) }\end{array}$ & $\begin{array}{l}35.2(10.9) \\
24.0-54.0\end{array}$ & $\begin{array}{l}34.8(8.1) \\
21.0-48.0\end{array}$ \\
\hline $\begin{array}{l}\text { Weight, kg } \\
\text { Mean (SD) } \\
\text { Range (min-max) }\end{array}$ & $\begin{array}{l}78.9(14.1) \\
56.0-103\end{array}$ & $\begin{array}{l}77.7(9.4) \\
60.0-93.0\end{array}$ \\
\hline $\begin{array}{l}\text { Height, cm } \\
\text { Mean (SD) } \\
\text { Range (min-max) }\end{array}$ & $\begin{array}{l}174(9) \\
154-186\end{array}$ & $\begin{array}{l}174(7) \\
161-186\end{array}$ \\
\hline $\begin{array}{l}\text { Body mass index }\left(\mathrm{kg} / \mathrm{m}^{2}\right) \\
\text { Mean (SD) } \\
\text { Range (min-max) }\end{array}$ & $\begin{array}{l}25.8(3.2) \\
19.5-30.0\end{array}$ & $\begin{array}{l}25.7(2.9) \\
20.4-29.6\end{array}$ \\
\hline
\end{tabular}

$\mathrm{SD}$, standard deviation

Table 2: Summary of subject demographic characteristics. 

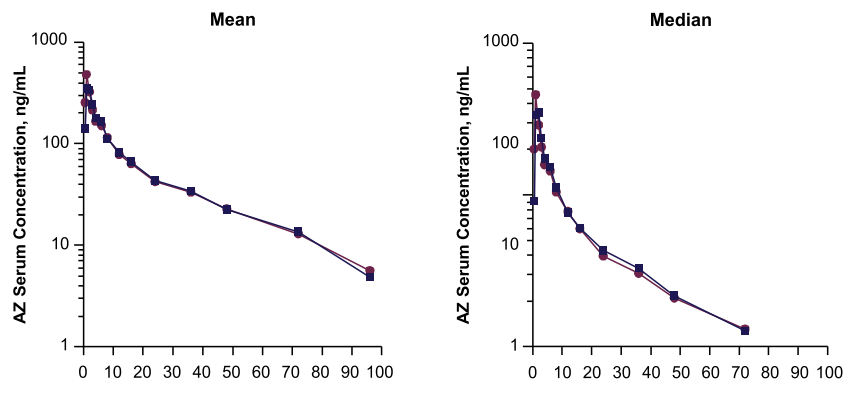

$\rightarrow$ AZCQ combination $-\mathrm{AZ}+\mathrm{CQ}$

AZCQ: fixed-dose combination tablet of $A Z$ and $C Q ; A Z+C Q$ : coadministered individual tablets of commercially available $\mathrm{AZ}$ and $\mathrm{CQ}$ tablets

Figure 1a: Mean and median serum concentration-time profiles of azithromycin by treatment group (semi-log plots). $A Z C Q=$ fixed-dose combination tablet of azithromycin $(A Z)$ and chloroquine $(C Q) ; A Z+C Q=$ coadministered commercially available individual tablets of $A Z$ and $C Q$.

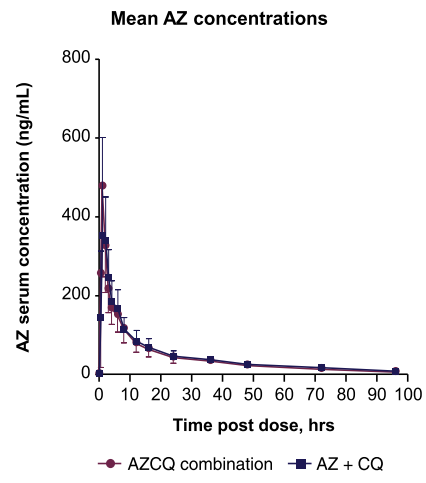

Figure 1b: Mean serum concentration-time profiles of azithromycin by treatment group (linear plots). $A Z C Q=$ fixed-dose combination tablet of azithromycin (AZ) and chloroquine $(C Q) ; A Z+C Q=$ coadministered commercially available individual tablets of $A Z$ and $C Q$.

Plasma chloroquine pharmacokinetics: Mean and median plasma CQ concentrations versus time profiles for the two treatment groups are presented as semi-log plots in figure 2a. The mean plasma CQ concentration -time profiles with associated standard deviation (SD) are also presented as linear plots in figure $2 \mathrm{~b}$. The median CQ concentrations between 2 and 12 hours post dose were lower with the two AZCQ tablets than with the coadministered commercially available individual CQ tablets. After 12 hours post dose, the median plasma CQ concentration-time profiles were similar between the two treatment groups.

The PK parameter values are descriptively summarized in table 3, and statistical analysis results of plasma CQ exposure parameter for bioavailability assessment are presented in table 4 . Variability in $\mathrm{AUC}_{\text {last }}(\mathrm{CV}, 30 \%-35 \%)$ and $\mathrm{C}_{\max }(\mathrm{CV}, 34 \%-36 \%)$ estimates for CQ were similar between the two treatment groups. The $\mathrm{AUC}_{\text {last }}$ estimates of CQ following the two treatments were similar. The ratio of adjusted geometric means of $\mathrm{AUC}_{\text {last }}$ following the administration of the two AZCQ tablets was $99.1 \%(90 \%$ CI, $84.0 \%, 117 \%)$ compared with the coadministered commercially available individual tablet of CQ. Therefore, the relative bioavailability value of the test treatment versus the reference treatment was $99.1 \%$ for CQ. The $\mathrm{C}_{\max }$ values of CQ were generally achieved by 1 hour post dose for the fixed-dose AZCQ combination tablets and by 2 hours post dose for the coadministered commercially available individual tablet of CQ. The $\mathrm{C}_{\max }$ value of CQ for the AZCQ combination tablets was approximately $11.0 \%$ lower than that observed following the coadministration of the commercially available individual tablets of $\mathrm{AZ}$ and $\mathrm{CQ}$.

\begin{tabular}{|c|c|c|}
\hline $\begin{array}{l}\text { Pharmacokinetic } \\
\text { Parameter }\end{array}$ & $\begin{array}{l}\text { Combination Tablets } \\
\text { (2×Azithromycin } 250 \mathrm{mg} / \\
\text { Chloroquine } 155 \mathrm{mg}) \\
(\mathrm{n}=20)\end{array}$ & $\begin{array}{l}\text { Individual Tablets } \\
\text { (Azithromycin } 500 \\
\text { mg+Chloroquine } 300 \mathrm{mg} \text { ) } \\
(\mathrm{n}=20)\end{array}$ \\
\hline \multicolumn{3}{|l|}{ Azithromycin } \\
\hline $\mathrm{AUC}_{\text {last }}{ }^{\mathrm{a}}(\mathrm{ng} \cdot \mathrm{h} / \mathrm{mL})$ & $3910(30)$ & $3877(32)$ \\
\hline $\mathrm{C}_{\max }{ }^{\mathrm{a}}(\mathrm{ng} / \mathrm{mL})$ & $496(40)$ & $437(38)$ \\
\hline $\mathrm{T}_{\max }^{\mathrm{b}}(\mathrm{h})$ & $1.00(0.50-2.00)$ & $1.52(0.50-3.00)$ \\
\hline \multicolumn{3}{|l|}{ Chloroquine } \\
\hline $\mathrm{AUC}_{\text {last }}{ }^{\mathrm{a}}(\mathrm{ng} \cdot \mathrm{h} / \mathrm{mL})$ & 3252 (35) & $3280(30)$ \\
\hline $\mathrm{C}_{\max }{ }^{\mathrm{a}}(\mathrm{ng} / \mathrm{mL})$ & $95.8(36)$ & $108(34)$ \\
\hline $\mathrm{T}_{\max }^{\mathrm{b}}(\mathrm{h})$ & $1.01(1.00-6.00)$ & $2.00(0.50-12.00)$ \\
\hline
\end{tabular}

$A \cup C_{\text {last }}=$ area under the drug concentration-time profile from time zero to the time of last quantifiable concentration $\mathrm{C}_{\max }=$ maximum concentration, $\mathrm{T}_{\max }=$ time to maximum concentration, ${ }^{\mathrm{a}} \mathrm{Geometric}$ mean (CV\%), ${ }^{\mathrm{b}}$ Median (range).

Table 3: Summary of serum azithromycin and plasma chloroquine pharmacokinetic parameter values.

\begin{tabular}{|c|c|c|c|c|c|}
\hline \multirow{2}{*}{$\begin{array}{l}\text { Parameter } \\
\text { (units) }\end{array}$} & \multirow[b]{2}{*}{ Test $^{a}$} & \multirow[b]{2}{*}{ Reference $^{a}$} & \multirow[b]{2}{*}{ Ratio $(\%)^{\mathrm{b}}$} & \multicolumn{2}{|c|}{$90 \%$ Confidence Interval } \\
\hline & & & & Lower & Upper \\
\hline \multicolumn{6}{|l|}{ Azithromycin } \\
\hline $\mathrm{C}_{\max }(\mathrm{ng} / \mathrm{mL})$ & 496 & 437 & 113 & 91.6 & 141 \\
\hline $\begin{array}{l}A \cup C_{\text {l }} \text { a s } t \\
(n g \cdot h / m L)\end{array}$ & 3910 & 3880 & 101 & 85.4 & 119 \\
\hline \multicolumn{6}{|l|}{ Chloroquine } \\
\hline $\mathrm{C}_{\max }(\mathrm{ng} / \mathrm{mL})$ & 95.8 & 108 & 89.0 & 74.4 & 106 \\
\hline $\begin{array}{l}A \cup C_{\text {l a s } t} \\
(\mathrm{ng} \cdot \mathrm{h} / \mathrm{mL})\end{array}$ & 3250 & 3281 & 99.1 & 84.0 & 117 \\
\hline
\end{tabular}

Test=2×azithromycin $250 \mathrm{mg} / \mathrm{chloroquine} 155 \mathrm{mg}$ fixed-combination tablet. Reference $=$ commercially available azithromycin $500 \mathrm{mg}$ tablet+chloroquine 300 mg tablet.

$\mathrm{C}_{\text {max }}=$ maximum concentration

AUบ $C_{\text {iast }}=$ area under the drug concentration-time profile from time zero to the time of last quantifiable concentration

${ }^{a}$ Adjusted geometric mean values.

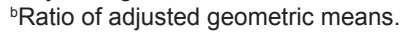

Table 4: Summary of statistical analysis of pharmacokinetic parameters $\mathrm{AUC}_{\text {las }}$ and $\mathrm{C}_{\max }$.

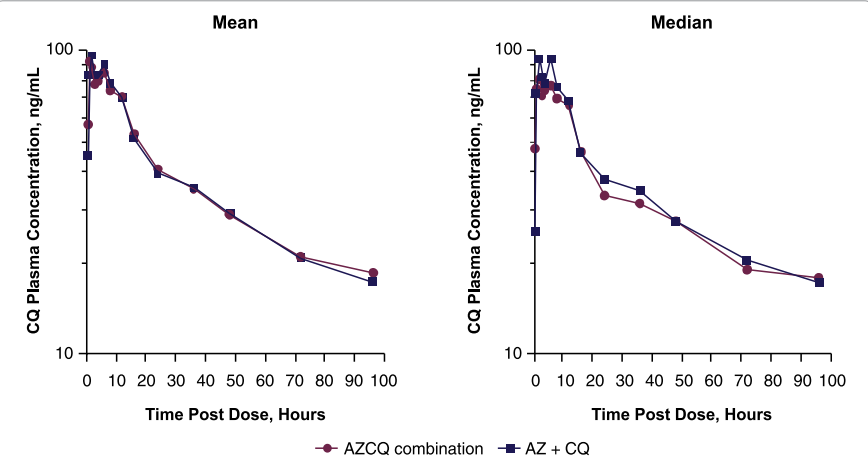

AZCQ: fixed-dose combination tablet of $A Z$ and $C Q ; A Z+C Q$ : coadministered individual tablets of commercially available $A Z$ and $C Q$ tablets

Figure 2a: Mean and median plasma concentration-time profiles of chloroquine by treatment group (semi-log plots). $A Z C Q=$ fixed-dose combination tablet of azithromycin ( $\mathrm{AZ}$ ) and chloroquine (CQ); $A Z+C Q=$ coadministered commercially available individual tablets of $A Z$ and $C Q$. 


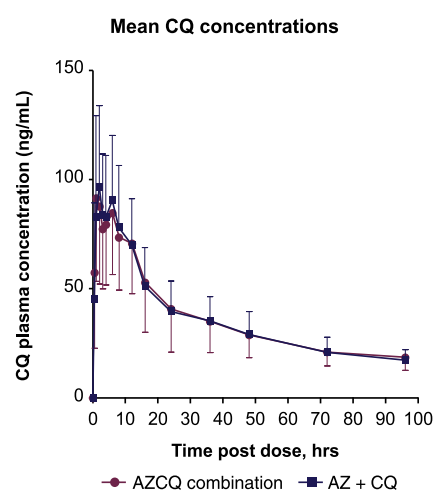

Figure 2b: Mean plasma concentration-time profile of chloroquine by treatment group (linear plots). AZCQ=fixed-dose combination tablet of azithromycin (AZ) and chloroquine $(C Q) ; A Z+C Q=$ coadministered commercially available individual tablets of $A Z$ and $C Q$.

\section{Safety}

Both test and reference treatments were well tolerated, with no serious AEs, deaths, or discontinuations due to AEs reported. The most frequently reported AEs were gastrointestinal tract-related, diarrhea and nausea, each of which were reported in two subjects in the AZCQ group and 1 subject in the group coadministered the commercially available individual tablets of $\mathrm{AZ}$ and $\mathrm{CQ}$. All AEs were mild to moderate in severity. Most AEs resolved without intervention.

\section{Discussion}

Based on systemic exposure, the results of this clinical pharmacology study showed comparable bioavailability of the two AZCQ tablets and the coadministered commercially available individual tablets of $\mathrm{AZ}$ and CQ. The small difference in $\mathrm{C}_{\text {max }}$ between the two treatments is unlikely to have a significant clinical impact. Both the AZCQ combination tablets and the coadministered commercially available individual tablets of AZ and CQ were well tolerated. Further, the development of a regimen of a fixed-dose AZCQ combination tablet formulation will greatly increase compliance by providing convenient dosing and will also decrease the likelihood of the development of resistance of $P$. falciparum to individual drug components of the tablet. Currently, this fixed-dose AZCQ combination tablet formulation is being evaluated in two ongoing Phase 3 studies on IPTp (ClinicalTrials.gov Identifiers: NCT01103713 and NCT01103063).

\section{Acknowledgments}

This study was sponsored by Pfizer Inc. Medical writing support was provided by Aruna Seth, PhD, of UBC Scientific Solutions and was funded by Pfizer Inc.

\section{References}

1. Dellicour S, Tatem AJ, Guerra CA, Snow RW, ter Kuile FO (2010) Quantifying the number of pregnancies at risk of malaria in 2007: a demographic study. PLoS Med 7: e1000221.

2. World Health Organization (2007) Malaria in pregnancy. Guidelines for measuring key monitoring and evlauation indicators.

3. Biswas S (2001) In-vitro antimalarial activity of azithromycin against chloroquine sensitive and chloroquine resistant Plasmodium falciparum. J Postgrad Med 47: $240-243$.

4. Dunne MW, Singh N, Shukla M, Valecha N, Bhattacharyya PC, et al. (2005) A multicenter study of azithromycin, alone and in combination with chloroquine, for the treatment of acute uncomplicated Plasmodium falciparum malaria in India. J Infect Dis 191: 1582-1588.

5. Ohrt C, Willingmyre GD, Lee P, Knirsch C, Milhous W (2002) Assessment of azithromycin in combination with other antimalarial drugs against Plasmodium falciparum in vitro. Antimicrob Agents Chemother 46: 2518-2524.

6. Chandra R (2007) A phase 3, randomized, open-label, comparative tria of azithromycin plus chloroquine versus mefloquine for the treatment of uncomplicated Plasmodium falciparum malaria in Africa. Proceedings of the 56th Annual Meeting of American Society of Tropical Medicine and Hygiene.

7. Chandra R, Lewis D, Moran D, Dubashi N, Sarkar S, et al. (2008) A phase 2 open-label, non-comparative trial of azithromycin $2 \mathrm{~g}$ plus chloroquine 600 $\mathrm{mg}$ base daily for three days for the treatment of uncomplicated Plasmodium falciparum malaria. Am J Trop Med Hyg 79: 11.

8. Chico RM, Chandramohan D (2011) Azithromycin plus chloroquine: combination therapy for protection against malaria and sexually transmitted infections in pregnancy. Expert Opin Drug Metab Toxicol 7: 1153-1167.

9. Cook JA, Randinitis EJ, Bramson CR, Wesche DL (2006) Lack of a pharmacokinetic interaction between azithromycin and chloroquine. Am J Trop Med Hyg 74: 407-412.

10. Greenwood B, Alonso P, ter Kuile FO, Hill J, Steketee RW (2007) Malaria in pregnancy: priorities for research. Lancet Infect Dis 7: 169-174. 